\title{
Effective engagement of male partners of adolescent girls and young women in Uganda
}

Population Council

Follow this and additional works at: https://knowledgecommons.popcouncil.org/departments_sbsr-hiv

Part of the Demography, Population, and Ecology Commons, Family, Life Course, and Society Commons, International Public Health Commons, Medicine and Health Commons, and the Women's Health Commons How does access to this work benefit you? Let us know!

\section{Recommended Citation}

Population Council. 2017. "Effective engagement of male partners of adolescent girls and young women in Uganda," Activity brief. Washington, DC: Population Council. 


\section{EFFECTIVE ENGAGEMENT OF MALE PARTNERS OF ADOLESCENT GIRLS AND YOUNG WOMEN IN HIV SERVICES}

Despite significant strides in curtailing the HIV epidemic in the 1990s and 2000s, Uganda currently has an adult HIV prevalence of 7.6 percent. Further, HIV prevalence is higher among adolescent girls and young women (AGYW) ages 15-24 compared to their male peers (3.7 percent vs. 2.3 percent). ${ }^{1}$ AGYW in Uganda, as in many countries, are particularly vulnerable to HIV due to a host of reasons, including economic disadvantage and lack of power to negotiate condom use or refuse sex with their male partners-many of whom are older and/or engage in high-risk behaviors.

Men's uptake of HIV testing and treatment falls far short of that needed to significantly decrease new infections among their generally younger female partners. It is estimated that 45.6 percent of men in Uganda received an HIV test in the past 12 months and know their results, compared with 57.1 percent of women. Men living with HIV in Uganda often enter care late and start treatment when they are at an advanced stage of disease. ${ }^{1}$ Further, voluntary medical male circumcision uptake, while increasing, remains suboptimal with only 40 percent of adult males in the country circumcised as of late $2014 .{ }^{1}$ Bolstering men's engagement in HIV services, therefore, is critical for their own health and that of their partners.

The Ugandan government is responding to these challenges by strengthening and scaling up a variety of strategies to increase men's uptake of HIV services. These strategies, supported by the U.S. President's Emergency Plan For AIDS Relief (PEPFAR) and other initiatives, include expanding male-friendly HIV testing services and linkages to care, increasing awareness of these services through intensive outreach, and improving systems to link HIV-positive men to care and treatment.

The Population Council is conducting implementation research in collaboration with local partner organizations to learn more about men's relationships with AGYW and how HIV services can better engage themtwo neglected areas of research. Similar studies are being conducted in South Africa, Swaziland, and Malawi. Learnings from these studies will be valuable for informing ongoing programming in Uganda and the region, as well as HIV prevention, care, and treatment efforts for AGYW and their male partners globally, particularly in this era of test and start.

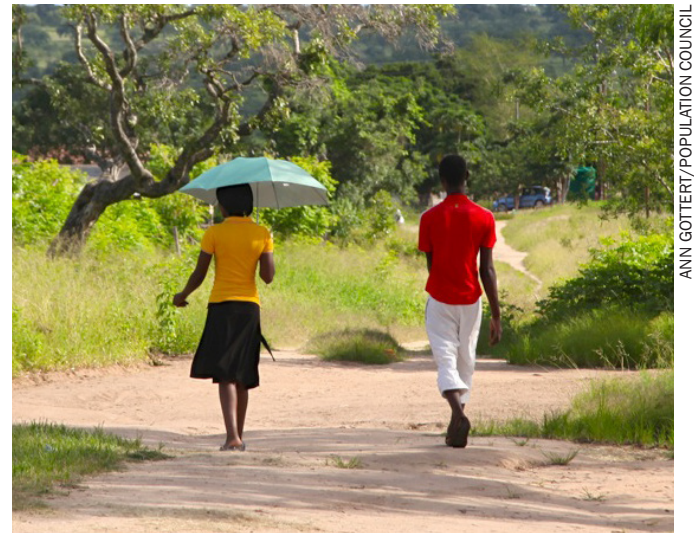

Exploring men's perspectives about their relationships with AGYW and how HIV services can better engage them will be valuable for informing ongoing HIV prevention, care, and treatment efforts.

\section{Research Partners:}

Child Health \& Development Centre, Makerere University College of Health Sciences, School of Medicine

Location: Peri-urban and rural sites in Gulu, Sembabule, and Mukono districts

\section{Study Duration: 2016-2018}

Funder: Bill \& Melinda Gates Foundation

For more information, contact Ann Gottert (agottert@popcouncil.org), or Godfrey Siu (gsiu@chdc.mak.ac.ug). 


\section{POPULATION COUNCIL'S DREAMS IMPLEMENTATION RESEARCH}

This study is part of a portfolio of implementation science studies the Population Council is conducting, with funding from the Bill \& Melinda Gates Foundation, related to the DREAMS (Determined, Resilient, Empowered AIDS-free, Mentored, and Safe) Partnership. This Partnership aims to significantly reduce new HIV infections among AGYW in 10 countries in sub-Saharan Africa, including Uganda. Our studies are exploring whether the intended beneficiaries-AGYW and their male partners-are being reached and retained in services, how different intervention components are being delivered to each group, and ultimately whether HIV risk among AGYW is being reduced. carried out with a sub-sample of the men interviewed previously (forming a qualitative cohort). Finally, FGDs will be conducted with key informants including DREAMS outreach and HIV service staff to explore perceived successes and challenges of strategies to link men to services.

\section{RESEARCH UTILIZATION}

We will actively engage key stakeholders throughout the study, including in interpreting the findings, formulating program and policy recommendations, and supporting their adoption in Uganda and beyond. Stakeholders in Uganda include, among others, the Ministry of Health, the Uganda National AIDS Commission, implementing partners such as MildMay, Strengthening Decentralization for Sustainability, Makerere University Walter Reed Project, PEPFAR, and other civil society groups.

\section{OUR RESEARCH}

Using mixed methods and capturing multiple perspectives, we seek to examine male partners' characteristics and perspectives and assess the successes and challenges of the intervention strategies.

Across the three districts, we will conduct focus group discussions (FGDs) with key informants, including community opinion leaders, DREAMS implementing partner staff and HIV service staff. In addition, we will carry out in-depth interviews with approximately 90 male partners of AGYW (30 per site), to understand sexual relationship dynamics, men's perceptions of HIV risk, their knowledge of HIV prevention and transmission, and insights into potential strategies to decrease their HIV risk, including HIV testing and treatment services.

We will then conduct a secondary analysis of monitoring data that will yield information about the reach of DREAMS-related HIV programming and men's uptake of HIV testing, care and treatment across the intervention period. To explore individual reasons for uptake and non-uptake in more depth, in-depth interviews will be

\section{WHAT WILL WE LEARN?}

This innovative implementation science study will generate valuable evidence about:

- The diversity and dynamics of relationships between men and AGYW in Uganda.

- Men's perceptions about how HIV services can best respond to their needs, and their decisionmaking about these services in the context of new test and start policies.

- The effectiveness of different strategies to reach the right men with the right services.

- Implementing partners' evolving, on-theground processes and experiences with these strategies-information that is rarely systematically documented or disseminated.

${ }^{1}$ Ugandan AIDS Commission. 2015. The HIV and AIDS Uganda Country Progress Report 2014. Kampala: Uganda AIDS Commission.

2PEPFAR-Uganda. In: Council P, editor. 2016.

POPULATION COUNCIL

Ideas. Evidence. Impact.
The Population Council confronts critical health and development issues-from stopping the spread of HIV to improving reproductive health and ensuring that young people lead full and productive lives. Through biomedical, social science and public health research in about 50 countries, the Council works with our partners to deliver solutions that lead to more effective policies, programs, and technologies to improve lives worldwide. Established in 1952 and headquartered in New York, the Council is a nongovernmental, nonprofit organization with an international board of trustees. popcouncil.org

Suggested citation: Population Council. 2017. "Effective engagement of male partners of adolescent girls and young women in hiv services: implementation science research in Uganda," DREAMS Activity Brief. Washington, DC: Population Council. 